\title{
EXERCISE TOLERANCE IN TyPe - 2 Male Diabetics
}

\begin{abstract}
The objective of this study was to compare the exercise tolerance of a set of male diabetic Nigerians with non-diabetic male subjects. Ten male Type-2 diabetics between the ages of 35 and 50 years in good glycaemic control and ten male non-diabetic controls of similar age were exercised on the ergometer at uptake of $90 \%$ and $60 \%$ V02 max respectively for anaerobic and aerobic exercises. Cardiovascular and fatigue rates or times to fatigue were then determined in both groups.

In both diabetics and controls, the time to fatigue was significantly longer

\section{O DEBIYI DO, MSC (PT) ${ }^{1}$, OHWOVORIOLE AE ${ }^{2}$}

${ }^{1}$ Department of Physiotherapy, College of Medicine, University Of Lagos, Nigeria.

2 Department of Medicine, College Of Medicine, University Of Lagos, Nigeria.

during exercise at $60 \% \mathrm{VO}_{2 \max }$ than at $90 \% \mathrm{VO}_{2 \max }(P<0.01)$. During aerobic exercise, the mean times to fatigue were very similar in the diabetic and control men $\{427.5$ (38.0) secs. V 439.0 (56.9) secs. $p>0.1\}$. The diabetic men fatigued more easily than controls under anaerobic condition ( $p 0.1>p>0.05$ ).

Type 2 male diabetics with good glycaemic control appear to tolerate aerobic exercise as well as non-diabetic males, but less so during anaerobic exercise. This difference in aerobic and anaerobic exercise tolerance should be borne in mind in prescribing exercise regimes in patients with type 2 diabetes mellitus.
\end{abstract}

KEY WORDS: TYPE 2 DIABETICS, NIGERIANS, AEROBIC EXERCISE, ANAEROBIC EXERCISE, FATIGUE RATE.

\section{INTRODUCTION}

Physical exercise is helpful in improving the metabolic control of diabetics, especially in those with type 2 diabetes mellitus (DM), in the promotion of good health and the prevention of diabetes mellitus ( Ivy 1997). Before prescribing exercise as a therapeutic and/or preventive measure, it is important to appreciate the likely response of the individual to such an exercise. In patients whose DM is well controlled, exercise may ameliorate the condition further (Larsen et al 1997). On the other hand exercise worsens the metabolic state in diabetics in whom glycaemic control is poor and could precipitate diabetes ketoacidosis in such patients (Perry et al 1993).

The two main forms of DM: Type1 DM and Type $2 \mathrm{DM}$, benefit from exercising but patients with Type $2 \mathrm{DM}$ appear to benefit more (Franz 1997). In clinical practice, type $2 \mathrm{DM}$ accounts for over 90 percent of the diabetic clinic population (Franz 1997). Such patients need to be referred for physical therapy - for adequate and closely monitored exercises. However, there appears to be little or no attention given to this area of study in Nigeria. Therefore, this preliminary report was designed to compare the fatigue states of a group of Type 2 diabetic Nigerians with those of a control group of similar age group, sex, and body size and activity level. The study was also designed to assess the responses of Type 2 diabetic men to aerobic and anaerobic exercises, since these two forms of exercises are the main ones employed in exercise therapy (ADA 1998).

\section{SUBJECTS AND METHODS}

The study was conducted at the College of Medicine of the University of Lagos, Lagos Nigeria. A sample of convenience of ten male Type 2 diabetic patients with good metabolic control (fasting plasma glucose $<120 \mathrm{mg} / \mathrm{dl}$ ), meeting the inclusion criteria was recruited into the study from the Diabetes Clinic of the Lagos University Teaching Hospital. To qualify for inclusion in the study, the persons must have been diagnosed diabetic using standard criteria (WHO 1985), and should be between the ages of 35 and 50 years, and be in good glycaemic control (fasting plasma glucose $<120 \mathrm{mg} / \mathrm{dl}$ ). Informed consent was obtained from each subject and only those who consented were studied. Ethical clearance was obtained from the ethical committee of the Lagos University Teaching
Hospital, Lagos, Nigeria. An invitation was extended until a total of 10 eligible patients had been recruited. All the diabetic subjects were on oral hypoglycaemic agents and had been on treatment for a minimum of two years (i.e. in stable state). Ten healthy subjects of similar age, sex, and body size and activity level and without a personal history of DM acted as controls. They were recruited from the hospital staff.

Both study and control subjects did not have a history of cardiovascular disease, arthritis, smoking or obesity. None of the subjects engaged in regular strenuous competitive exercise.

\section{PROCEDURE}

Each subject was given a pre-exercise review focusing on symptoms and signs of disease affecting the heart and blood vessels, eyes, kidneys and the nervous

\section{CORRESPONDENCE TO: \\ D.O. Odebiyi \\ Department Of Physiotherapy \\ College Of Medicine, \\ University Of Lagos \\ P.M.B. 12003, Lagos, Nigeria \\ e-mail: femiodebiyi@yahoo.com}


system as suggested by the American Diabetes Association (ADA 1998).

On the test day, the subject was invited into an air-conditioned room. The height was measured with health -0-meters scale with the subject dressed in sports wear and without shoes. Lower limb length was measured using a tape measure. Measurement was taking from the anterior superior iliac spine (ASIS) to the tip of the medial malleolus on each side of the body. Weight and limb lengths of each subject were recorded. For the diabetic patients, the duration of DM was also recorded. Patients with diabetes had their blood glucose tested as well as urine test for glucose and ketones. Fasting plasma glucose was determined in the endocrine laboratory of the Department of Medicine using the glucose oxidase method. Urinalysis for glucose and ketones was performed using Multstix. The baseline (pre-exercise) heart rate and blood pressure were recorded. Counting the radial pulse for 30 minutes and expressing the rated on count per minute obtained heart rate. Blood pressure was obtained with the patient at rest by means of a mercury sphygmanometer (accouson), using standard procedures (WHO, 1999).

The predicted standard maximum oxygen consumption was determined, in order to establish exercise intensities, using the test and exercise intensities suggested by Astrand (Astrand, 1960). The room temperature was maintained at $27-28^{\circ} \mathrm{C}$ throughout the study period. Each subject was instructed on how to use the bicycle ergometer: A vertical Monak cycle ergometer exercise bike with an inbuilt speedometer and mechanical timer (Monak model 5134530.Quinton instrument, $305144^{\text {th }}$ aven. W seatle, W. A 98199) was used. The subjects were asked to exercise on the ergometer at a workload that required oxygen uptake of 90 percent (for anaerobic exercise) and 60 percent (for aerobic exercise) of the predicted standard $\mathrm{Vo}_{2 \max }$ respectively. An assistant blind to the diabetes status of the individuals motivated them to the point of fatigue. Fatigue was taken as the time at which the subject could no longer pedal on the ergometer at the set workload from the start of exercise. The time interval from the start of each exercise phase to the point of fatigue was recorded. Between workloads, the subject rested for 30 minutes during which time the cardiovascular indices (HR and BP) were expected to have returned to baseline values.

\section{Statistical methods}

Data analysis-including descriptive statistics and Pearson's correlation coefficient was performed using WHO statistical package EPI-info version 6. The averages of results are presented as mean (SEM). Significance of differences between group means was determined using a 2-tail student's t-test. A p-value of $<0.05$ was taken as the level of statistical significance.

\section{RESULTS}

The clinical features of the diabetic and control subjects, all of whom were males, are shown in Table 1. Except for the presence of diabetes, the two groups were similar in sex, age and weight distribution. However, the diabetics had a higher mean BMI than the controls.
The heart rate and pressure responses have been reported earlier (Odebiyi and Ohwovoriole, 1999). The heart rate of the subject did not return to the baseline values 30 minutes after anaerobic exercise (Table 2).

Table 3 displays the comparison of the time to fatigue in the study and control subjects performing anaerobic and aerobic exercises. There was no statistically significant difference between the groups, although, the control group showed slightly longer time to fatigue (diabetic V controls: $188 \pm 87.8$ V 241 \pm 115 seconds, $01>\mathrm{p}>0.05$ ), during the performance of anaerobic exercise. There was little or no difference in the time to fatigue in the two groups during aerobic exercise (diabetics V control: $428 \pm 162$ V $439 \pm 180, p>0.05$ ). Table 4 shows the correlation coefficient between fatigue time and some clinical features. Fatigue rate was strongly correlated to age, however, fatigue rate was not significantly correlated to BMI. Aerobic and anaerobic times to fatigue correlated well with each other.

See scattergram (Figure 1).

Table 1: Clinical Characteristics of the Subjects

\begin{tabular}{|c|c|c|c|}
\hline Variable & $\begin{array}{l}\text { TYPE } 2 \text { DIA BETIC } \\
X \pm \text { SEM (Range) }\end{array}$ & $\begin{array}{l}\text { NON-DIA BETIC } \\
X \pm \text { SEM (Range) }\end{array}$ & P-VALUES \\
\hline AGE (year) & $\begin{array}{lll}40.4 & 2.7 & (35-50)\end{array}$ & $\begin{array}{lll}39.9 & 1.11 & (55-47)\end{array}$ & $>0.05$ \\
\hline W eight $(\mathrm{kg})$ & $68.3 \quad 4.5 \quad(56-78)$ & $63.7 \quad 1.76 \quad(54-71)$ & $>0.05$ \\
\hline Height (m) & $1.720 .12(1.66-1.79)$ & $1.710 .02 \quad(1.65-1.79)$ & $>0.05$ \\
\hline BMI (kgm-2) & $23.4 \quad 1.56 \quad(20.57-25.48)$ & $21.70 .56 \quad(19.83-24.98)$ & $>0.05$ \\
\hline $\begin{array}{l}\text { Duration of } \\
\text { DM (Year) }\end{array}$ & $6.1 \quad 1.4$ & & \\
\hline
\end{tabular}

Table 2: Basal (Resting) Heart Rate (HR) and Heart Rate after 30 minutes period of rest following Anaerobic Exercise

\begin{tabular}{|l|ll|l|l|}
\hline & $\begin{array}{l}\text { BASAL HEART RATE } \\
\mathbf{X} \pm \text { SEM (Range) }\end{array}$ & $\begin{array}{l}\text { HR 30 MIN UTES AFTER } \\
\text { AEROBIC EXERCISE } \\
\text { X } \pm \text { SEM (Range) }\end{array}$ & P-VALUES \\
\hline Diabetics & $78.6 \quad(1.7)[76-86]$ & $85.0(1.4)[80-92]$ & $<0.05$ \\
\hline Non - Diabetics & $69.2 \quad(2.0)[64-76]$ & $75.6(0.2)[64-80]$ & $<0.05$ \\
\hline
\end{tabular}

Table 3: Comparison of time to Fatigue during the Performance of Exercise

\begin{tabular}{|c|c|c|}
\hline & $\begin{array}{l}\text { FATIG UE TIMES IN SECOND } \\
\text { AN AEROBIC EXERCISE }\end{array}$ & $\begin{array}{l}\text { Mean (SEM)[Range] } \\
\text { AERO BIC EXERCISE }\end{array}$ \\
\hline All subjects & $214 \quad(83.9) \quad\left[\begin{array}{lll}12 & -465\end{array}\right]$ & $433(146) \quad[210-760]$ \\
\hline Diabetics & $188 \quad(87.8) \quad\left[\begin{array}{lll}125 & -225]\end{array}\right.$ & $428(1629)\left[\begin{array}{lll}330 & -680\end{array}\right]$ \\
\hline Controls & 214 (115) [120 -465] & $439(180) \quad[210-760]$ \\
\hline
\end{tabular}


Table 4: Correlation Coefficients between Fatigue Time and some Clinical Features

\begin{tabular}{|l|c|c|}
\hline \multicolumn{1}{|c|}{ Variable Correlation } & \multicolumn{2}{c|}{ Correlation Coefficient } \\
\hline & Type 2 diabetics & N on-diabetics \\
\hline Age and BM I & -0.129 & +0.302 \\
\hline Age and fatigue rate (anaerobic) & -0.054 & +0.054 \\
\hline BMI and fatigue rate (anaerobic) & -0.131 & +0.199 \\
\hline Age and fatigue rate (aerobic) & -0.054 & +0.039 \\
\hline Fatigue rate (aero.) and fatigue rate (anaero) & +0.712 & +0.712 \\
\hline Duration of dm and fatigue rate (anaero) & +0.140 & ---- \\
\hline Resting heart rate and fatigue rate (aero) & +0.07 & -0.108 \\
\hline Resting heart rate and fatigue rate (anaero) & -0.18 & -0.218 \\
\hline
\end{tabular}

Figure 1: Correlation between anaerobic and aerobic fatigue time in the diabetic subjects.

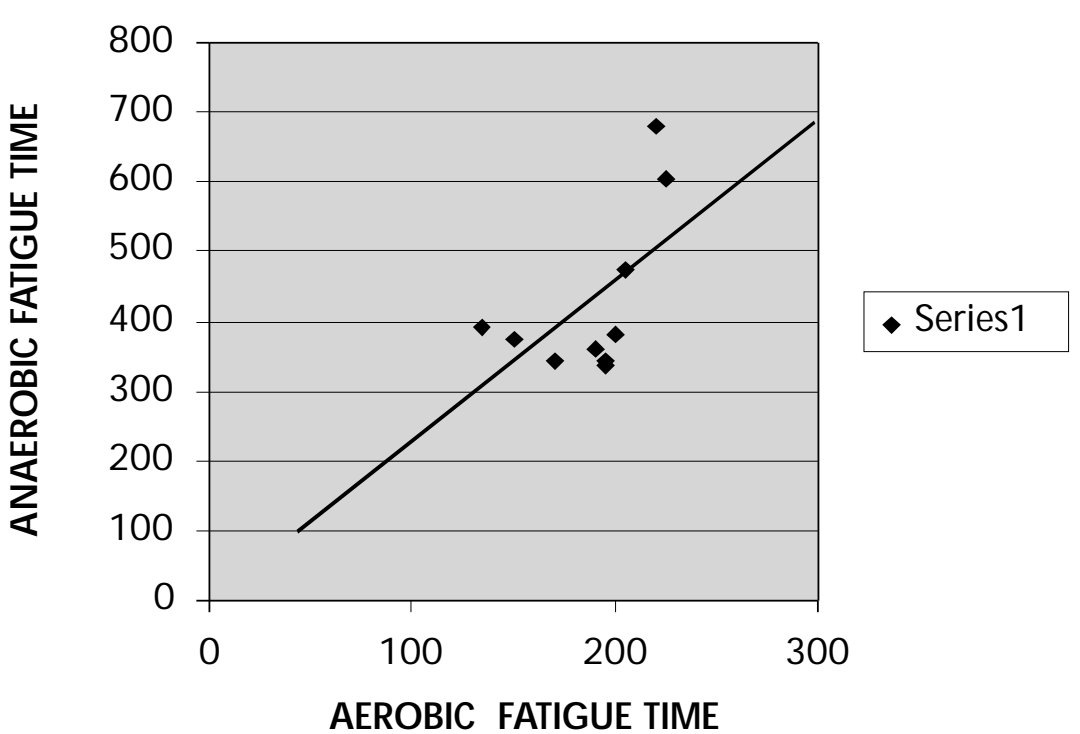

\section{DISCUSSION}

Exercise is one of the main cornerstones of managing Type $2 \mathrm{DM}$, the others being education, diet, and drugs. The benefits of exercise as part of the therapy in diabetes include lowering of glycaemia in the short term and in the long term as indicated in the changes in HbAic levels (Larsen et al 1997; Honkola et al 1997), improved insulin sensitivity, an adjunct to weight reduction, improving the lipid profile and enhancement of a general sense of well being and self esteem (Vranic and Berger 1979). Exercise has also been shown to help prevent or delay the onset of Type $2 \mathrm{DM}$ in those at risk (Wing et al 1998).

It is important, therefore, that all, especially those with Type 2 DM, be encouraged to exercise. Information for this insignificant difference could be autonomic neuropathy (Wheeler and Watkins, 1973), which was not specifically tested for in this study. Autonomic neuropathy would be expected in some of the subjects with long standing DM as there is a close relationship between the development of autonomic neuropathy and duration of diabetes (Vink and Mitchell, 1998). Neuronal failure, that is, the easy fatigability on transmission, which has been observed in diabetics could also account for the reduction in exercise tolerance observed in this study (Osvaldo, 1973).

It has also been suggested that there is a reduction in the cellular storage of ATP and creatine phosphate, particularly, in Type 2 diabetics (Karlsson and Saltin, 1970). This results in reduced capacity for glycogen synthesis, storage and uses and consequently leads to reduced exercise tolerance. These events are complicated by increased production of muscle and serum lactic acid that is a major mediator of the process of fatigue (Karlsson and Saltin, 1970). The failure of the resting "heart rate" to return to the baseline value, particularly in the diabetic subjects, is an indicator that the 30 minute rest period between the exercise intensities was inadequate. Therefore, enough "rest period" should be allowed for diabetics during therapeutic exercise.

The findings of this study are in line with common observations in clinical settings. However, they do not agree with the findings of Wolfe and Dicarlo (1983) who reported that Type 1 (insulin dependent) diabetics showed greater resistance to fatigue (i.e. good exercise tolerance) and lesser resistance to fatigue (i.e. poor exercise tolerance) than non-diabetics during anaerobic exercise and aerobic exercise respectively (Wolfe and Dicarlo, 1983). The reasons for this difference may not be unconnected to the marked differences in the clinical characteristics of the subjects in the two studies- theirs was on Type 1 diabetics whereas ours was on Type 2 diabetics.

Based on the findings of this study, it would appear that diabetics engaging in exercise might demonstrate a lower resistance to fatigue particularly during anaerobic exercise (i.e. exercise of high 
intensity and short duration). It therefore stands to reason that aerobic exercise (i.e. exercise of low intensity and long duration) is preferable for Type 2 diabetic patients. The exact role of anaerobic exercises in the management of diabetes mellitus or during the rehabilitation of diabetics deserves to be studied further.

\section{REFERENCES}

American Diabetes Association 1998 Diabetes Mellitus and Exercise. Position Statement. Diabetes Care. 21: 540 - 544

World Health Organisation 1999 International Society of Hypertension, Guidelines for the management of Hypertension. Blood pressure 8 (Supplement 1): 9-43

Astrand PO 1960 Aerobic work capacity in men and women with special reference to age. Acta Physiologica Scandinvia. 49 (supp 169): $45-60$

Franz MJ 1997 Lifestyle modifications for diabetes management. Endocrinology and Metabolic Journal of North America. 26: $499-510$
Honkola A, Forsen T, Eriksson J 1997 Resistance training improves the metabolic profile in individual with type 2 diabetes. Acta Diabetologica. 34; 245-8

Ivy JC 1997 Role of exercise in the prevention and treatment of insulin resistance and noninsulin dependent diabetes mellitus. Sports Medicine. 24: 321-336

Karlsson J, Saltin B 1970 Lactate,ATP and $\mathrm{CP}$ in walking muscle during exhaustive exercise in man. Journal of Applied Physiology. 29: 598-602

Odebiyi DO, Ohwovoriole AE 1999 Blood pressure and heart rate responses to exercise in non insulin dependent diabetic males. Nigerian Journal of Internal Medicine. 2: 4-9

Larsen JJ, Dela F, Kjaer M, Galbo H 1997 The effect of moderate exercise on postprandial glucose homoestasis in NIDDM patients. Diabetologia. 40:447 - 453

Osvaldo M 1973 Neuromuscular function defect in diabetes. Diabetes. 22.9

Perry IJ, Wannamethex SG, Walker MK, Shaper AG 1993 Sporting activity and hyperglycaemia in middle-aged men. Diabetes Care 1993. 16:581 - 583
Vink A, Mitchell B. 1998 Clinical aspects of diabetic neuropathics. Metabolic Review. 4:223 -253

Vranic M, Berger M. 1979 Exercise and diabetes mellitus. Diabetologia. 28: 142 - 167

Wheeler T, Watkins PJ 1973 Cardiac Denervation in diabetes. British Medical Journal. 4:584 -589

Wing RR, Venditti E, Jakici JM, Pelley BA, Lang W 1998 Lifestyle Intervention in Overweight Individuals with a family history of diabetes. Diabetes Care. 21: 350 -9

Wolfe PI, Dicarlo S 1983 Fatigue rate during anaerobic and aerobic exercise in insulin dependent diabetics and non-diabetics. Physical Therapy. 63: 500-504.

World Health Organisation 1985 Diabetes mellitus. Technical Report Series No 727 Geneva. WHO

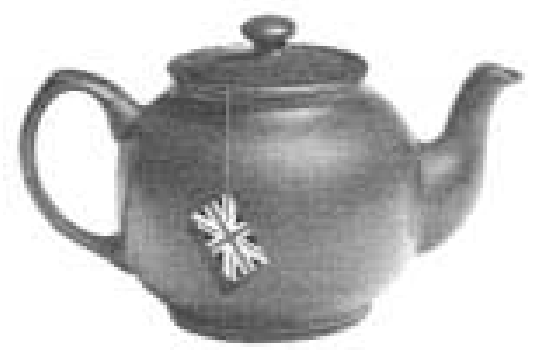

\section{Is working in the UK your cup of tea?}

Angela Shaw Associates have over 10 years experience in the successful placement of overseas therapists throughout the UK and Ireland.

If you're a Physiotherapist, Occupational Therapist or Speech and Language Therapist we offer a number of benefits including:

\section{Free tax advice $\square$ CPSM refund ${ }^{*}$ Accident Insurance - Enhanced rates of pay $\square$ Temporary and permanent positions Enormous range of opportunities throughout the UK and Ireland $\square$ Training allowance* $\square$ Holiday pay * Subject to qualifying status}

If you're looking to make the move contact one of our dedicated consultants today.

\section{Call free from South Africa today on 0800990767}

tel: +44 (0) 2085547691

email: asa@match.co.uk

web: www.asa-locums.co.uk a member of the match group

\section{$\mathbf{N}$ e w \\ M illennium Tim e to think of a change?}

Quality Locums are looking for quality personnel in all grades and specialities for work in the UK. Eligibility for a visa or work permit w ould be an advantage, but even if you are not eligible we would still like to hear from you as we may be able to help. Quality Locums are the largest independent Medical, Care and Education Agency in the UK and we have branches in South Africa and Australia. We need M edic al Staff of all specialities, Social Workers and Teachers urgently to fill full and part time positions throughout Great B ritain and Ireland. We are experts at helping you to take advantage of the opportunities in the UK. Why not call one of our managers today for an informal discussion.

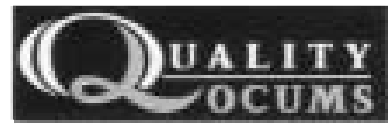

S onja Lew is Quality Locums Cape Town Tel: 0214625357

Fax: 0214625390

Email: QualityLocums@Worldonline.co.za

M a tt W a g ner Quality Locums Durban

Tel: 0313091471

Email: Wagner@yebo.co.za

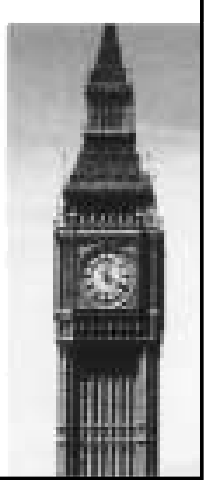

